\title{
Ein Beitrag zur Operation fremder Körper im äusseren Gehörgange
}

\author{
von \\ Dr. Voltolini, \\ Docent der Ohrenheilkunde an der Universität Breslau.
}

(Mit einem Holzschnitt.)

Den folgenden Fall theile ich nicht mit, um die zahllose Menge von Beschreibungen fremder Körper im äusseren Gehörgange noch um einen zu vermehren, sondern weil er ein newes Operations-Verfahren darbietet und gleichsam ein Triumph ist für die Berücksichtigung der anatomischen Verhältnisse bei Leiden des Gehörorganes, ohne welche Berücksichtigung der Bearbeitung der Ohrenheilkunde die reale also auch reelle Grundlage fehlt. Der Fall ist folgender:

Die 3jährige Louise L., Tochter eines Juristen in Ohlau, hatte sich beim Spielen ein Schrotkorn Nr. 3 oder 4 in das linke Ohr gesteckt. Das Kind musste Unbehagen im Ohre verspïren, weil es selbst die Angebörigen auf den Unfall aufmerksam machte. Der herbeigerufene Arzt suchte mittelst Instrumenten das Schrotkorn herauszustossen, aber vergeblich; der Gehörgang blatete und es musste von der Operation abgestanden werden. Das Kind wurde nunmehr, nach Verlauf vieler Tage zu mir nach Breslan gebracht. Am ersten Tage war es mir nicht möglich das Schrothorn trotz des hellen Sonnenlichtes zu exblicken: der "uussere Gehörgang war von fremdartigen Massen angefillt, wahrscheinlich Blutcoagula mit Schlein gemengt, die auch durch Injectionen nicht heraus befördert werden konnten. Ich liess deshalb zunächst eine Auflösung von Plumb. acet. anwenden; des anderen Tages gelang es mir bereits durch Einspritzungen jene fremden Massen zu entfernen und ich sah num klar und deutlich das Sehrotkorn dicht am Trommelfell, unten, liegen; der Gehörgang war frei und gesund. Geschwulst nicht vorhanden und befand sich
\end{abstract}


das Kind vollständig wohl und munter, obwohl das Schrotrorn etwa sehon 14 Tage im Ohre verweilte.

Ich machte mir nun zunächst die Gefahren klar, welche mit der gewaltsamen Entfernung des fremden Körpers und umgekehrt die, welche mit dem Liegenlassen desselben verbunden sind. Da das Schrotkorn unmittelbar am Trommelfelle lag, so war es bei der gewaltsamen Entferuung fast völlig unvermeidlich, dasselbe ohne Zerreissung des im kindlichen Alter so zarten Trommolfelles aus dem Gehörgange zu schaffen, zumal bei der unruhigen Haltung eines Kindes. Wäre dann aber der so kileine schwere Körper durch das Trommelfell in die Paukenhöble gelangt, so wäre sogar Gefahr für das Leben des Kindes eingetreten, denm Niemand hätte das Schrotkom wohl von dort herausgebracht. Andererseits hatte das Liegenbleiben des fremden Körpers im äusseren Gehörgange zunächst nicht viel zu bedeuten, wie bereits der Verlauf bewies. Ich hütete mich deshalb vor jeder Ueberstürzung. Zunächst suchte ioh durch mehrere Tage mittelst Einspritzungen das Schrotkorn $z \mathrm{n}$ entiemen, wobei ich das Kind verschiedene stellangen eimehmen liess; so legte ich es z. B. auf 2 Stïhle, die auf einen Tiseh gestellt wurden und liess den Kopf des Kindes zur Seite herabhängeu - aber Alles vergeblich. Ich beschloss nummehr einen Versuch mit der gewaltsamen Entfernung zu machen und da der Vater des Kindes vom Chloroform nichts wissen wollte, so wurde das Kind ron 2 Männem und 2 Mägdea gehalten, während ich beim Sonnerlichte zunächst mit einem Ohrlöffel, dann mit einer Enieförmigen Pincette das Schrotkorn zu entfernen suchte. Aber auch dies war vergeblich; die 4 Personen waren nicht im Stande das Kind so fest zu halten, dass ich ohne Gefahr der ernstlichen Verletzung des äusseren Gehörganges, resp. des Trommelfelles hätte znm Ziele gelangen können; auch blutete bereits etwas das Ohr. Der Ohrlöffel zeigte sich noch gefahrbringender als die Pincette, weil ich mit jenem durchaus zwischen Korn und Trommelfell gehen musste. Bei der Pincette trat der Uebelstand ein, dass sie am Korn selbst nicht weit genug geöfinet werden konnte, weil vorn an der Enge des Einganges des äusseren Gehörganges das Auseinandergehen der Branchen verhindert wurde. Tch beschloss demnach erst eine nene Pincette construiren zn lassen, welche die Uebelstände jener nicht darbot.

In den folgenden Tagen stellte ich noch einige Versuche mit Klebemitteln an; ein dicker gewichster Faden wurde in Fogelleim, ein andermal in geschmolzenes Emplastr. adhäsiv. getaucht, um so das Schrotkorn anzukleben. Auf dem Tische gelang dies Experiment mit einem Schrotkorn, aber nicht irn Ohre, weil das Kind nicht still hielt.

\section{Die neue hier gezeichnete Pincette hat folgende Vortheile:}

Man kann mit dem Theile a der Pinçette in eine Höhle eingehen, deren Fingang enger ist als der Grund und kann hier fremde Körper fassen. Bei $\mathrm{c}-\mathrm{c}$ und $\mathrm{a}$ ist ein Gelenk; drückt man auf die Branchen $\mathrm{d}-\mathrm{d}$, so schliesst sich die Pinçette, das heisst $\mathrm{b}$ nähert sich $\mathrm{b}$, die Theile a $\mathrm{b}$ sind auf die Fläche gebogen, damit man sich beim Operiren das Licht mit der Hand nicht fortnimmt.

In der Zeit während die Pinçette angefertigt wurde, hatte ich grade in meiner Vorlesung den Zuhörern das Trommelfell zu demonstriren und hierbei stieg mir der Gedanke auf, dass ein Schrotkorn 
aus dem Gehörgange fallen müsste, wenn man dem Ohre eine bestimmte Stellung gäbe und das Korn in Bewegung brächte. Vergegenwärtigen wir uns den äusseren Gehörgang: seine obere und lintere Wand bildet mit dem Trommelfell einen stumpfen Winkel, also eine schiefe, noch dazu sehr glatte Ebene (Trommelfell); die untere und vordere Wand bildet mit dem Trommelfell einen spitzen Winkel, dazu noch kommt, dass die vordere Wand einen Bogen macht und vor dem Trommelfell eine Vertiefung enthält, so dass hier Alles geboten ist, um ein Schrotkorn festzuhalten. Seine Herausbeförderung mit einem Obrlöffel ist deshalb um so schwieriger, ja gefährlicher, weil es nicht blos darauf ankommt, den Körper mittelst eines Ruckes nach aussen zu schnellen, sondern weil er über den Bogen der vordern Wand zugleich etwas gehoben werden muss - bei der Beleuchtung des Ohres kommt aber durch Neigung des Kopfes die vordere Wand nach unten. Bringt man nun aber das Ohr des Patienten in eine solche Lage, dass die obere, hintere Wand des Gehörganges nach unten zu liegen kommt, so muss das Schrotkorn aus dem spitzen Winkel auf der schicfen Ebene, welche das Trommelfell mit der oberen, hinteren Wand bildet, aus seiner eingebetteten Lage herausfallen. Zieht man hierbei noch die Ohrmuschel stark nach hinten und etwas nach oben, so ist der ganze knöcherne und knorplige Gehörgang an seiner oberen hinteren Wand in eine Ebene gebracht, auf der das Schrotkorn sogar aus dem Ohre herausfallen kann. Obwohl nun jene oben

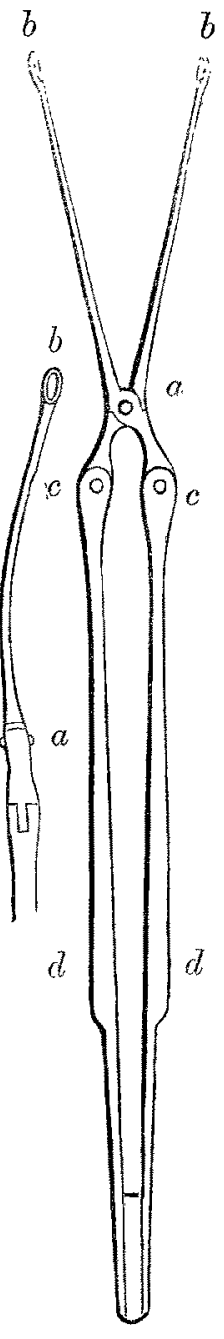
beschriebene Pincette bereits angefertigt war, so machte ich doch erst den Versuch mit dem angeführten Experimente.

Das Kind wurde wieder auf die 2 Stüle gelegt, die anf cinem Tische standen, und obwohl die Tante des Kindes sehr naiv meinte, jeder vernünftige Menseh muss das Kind auf die Scite legen zu der bevorstehenden Operation, so machte ich es jedoch jetzt nicht wie ein "vemünftiger" Menseh, sondern legte das Kind auf den Rücken und liess den Kopf ctwas uberhängen; ein Gehilfe verzog die Ohrmuschel nach hinten und oben. Jetzt, um das Schrotkorn in Bewegung zu setzen, máchte ich Einspritzungen; nach einigen spritzungen unterstuchte ich das Ohr - das Korn war bereits in der Mitte des Gehörganges einpassirt; nach weiteren Einspritzungen erschien es bereits am Eingange des meatus, so dass mali in Versuchung kam, wozu die Cmstehenden auch riethen, es jetzt mit einem Instrumente zu fassen. Hier- 
154 VOLTOLNA: Ein Beitr. x. Operation fremder Körper in äuss. Gehörgange.

vor fürchtete ich mich jedoch, weil, wenn dies nicht gelang, das Korn wieder zurückrollen konnte; ich wiederholte die Einspritzungen und plötzlich fiel das Schrotkorm aus dem Ohre heraus.

Somit war das Kind von dem fremden Körper befreit, ohne jegliche Beeinträchtigung des Gehörganges und Gehörvermögens und ohne dass irgend eine Nachkur nöthig gewesen wäre, die in anderen Fällen dem Arzte noch lange Zeit zu schaffen macht.

Ich erlaube mir hier noch einen andern Fall anzureihen, den ich bald nach dem obigen beobachtete und der auch einiges Interesse darbietet.

Ein Knabe von 13 Jahren hatte sich einen Johannisbrodkern in das Ohr gesteckt. Verschiedene vergebliche Versuche waren schon angestellt worden, den Kern zu entfernen, als dex Pat. etwa nach 14 Tagen zu mir kam. Der Gehörgang war bedeutend rerschwollen, sebr schmerzhaft and eiterte bereits. Es war mir, auch nach Injectionen, nicht möglish, den Kom dentlich zu erkennen, jedoch konnte ich ihn mit der Sonde erfiuhlen. Jeder Versuch, zwisehen den Kern und die Wand des Gehörganges einen Ohrloffel zu bringen, rief die wäthendsten Schmerzen hervor, weshalb ich zur Beseitigung der Entzündung erst durch mehrere Tage Einspritzungen und Bingiessungen von Alaun-Lösung verordnete. Als der Knabe eines Tages wieder zu mir kam, fiel mir ein gelblich weisser Fleck mitten im Lumen des Gehörganges in einer dunklen Masse auf. Ich musste diesen für Eiter halten, konnte aber nicht begreifen, wie hiex der Eiter gleichsam in der Luft schwebe, d, $b$. mitten im Lumen des Gehörganges, bis ich auf den Gedanken kam, dass in diesem warmen menschlichen Exühbete der Johanuisbrodken wohl schon keimen möchte - und so war es auch. Auf diese Entdeckung hin basirte ich mein weiteres Vertabren, denn jeh musste nun annehmen, dass der ganze Kern bereits weich geworden sei. Ich ging deshalb mit einem ziemlich scharfen Ohrlöfel in den Gehörgang, und stach jenen kräftig in den weichen Kern und entfernte mit Einem Ruck denselben sofort nach aussen. Der ganze Gehörgang zeigte sich nun versehwollen und in Eiterung begriffen; die Nachbehandlung dauerte lange Zeit. Der Kern hatte wohl das Doppelte bis Dreifache seiner Grösse erreicht.

Ich stellte nach vollbrachter Operation sofort einige Versuche an, in wie kurzer Zeit wohl ein Johannisbrodkern schon zu keimen anfange und fand, dass er in warmem Wasser durch 24 Stunden schon beginnt weich zu werden, nach zweimal 24 Stunden sieht man schon den Keim sich entwickeln. Für die Entfernung ähnlicher Körper möchte dieser Versuch fernerhin zu verwerthen sein. 